\title{
1 Structural colours reflect individual quality: a meta-analysis
}

2 Thomas E. White ${ }^{1,2}$

$3 \quad{ }^{1}$ School of Life and Environmental Sciences, The University of Sydney, Sydney, Australia 2106

$4 \quad{ }^{2}$ Corresponding author.

5

6 E-mail: thomas.white@sydney.edu.au

7 Keywords: condition dependent, honest signal, communication, iridescence, sexual selection

8 Word count (excluding abstract): 2489

9 Number of figures: 1

10 Number of tables: 1

11 Supplementary material: Supplementary figures and table 


\section{Abstract}

22 Ornamental colouration often communicates salient information to mates, and theory predicts

23 covariance between signal expression and individual quality. This has borne out among pigment-

24 based signals, but the potential for 'honesty' in structural colouration is unresolved. Here I

25 synthesised the available evidence to test this prediction via meta-analysis and found that,

26 overall, the expression of structurally coloured sexual signals is positively associated with

27 individual quality. The effects varied by measure of quality, however, with body condition and

28 immune function reliably encoded across taxa, but not age nor parasite resistance. The

29 relationship was apparent for both the colour and brightness of signals and was slightly stronger

30 for iridescent ornaments. These results suggest diverse pathways to the encoding and exchange

31 of information among structural colours, while highlighting outstanding questions as to the

32 development, visual ecology, and evolution of this striking adornment. 


\section{Introduction}

Colour is a ubiquitous channel of communication in nature and is showcased at an

44 extreme in the service of mate choice [1,2]. A central hypothesis in evolutionary biology is that

45 sexual selection has driven the elaboration of ornamental colouration into reliable indicators of

46 individual quality [3], with empirical tests guided by indicator and handicap models [4,5]. These

47 models argue that conspicuous displays are selectively favoured because their production is

48 differentially costly (handicap) and/or constrained (index) between individuals of varying

49 quality, and so encode honest information to potential mates. A prediction common to honesty-

50 based models is that signals should show heightened condition-dependent expression, and the

51 most robust support to date among ornamental colouration is found in carotenoid-based signals

52 [6,7]. As pigments that cannot be synthesised de novo, all carotenoids must ultimately be

53 acquired via diet before being incorporated into signals directly or following bioconversion. This

54 offers ample opportunity for selection to favour mechanistic links between foraging, metabolic

55 performance, and sexual signal expression (that is, the combined perceptual features of hue,

56 saturation, and brightness), which is now well established, at least among birds [8,9]. Relative to

57 our knowledge of pigment-based colouration, however, the potential for structural colours to

58 signal individual quality remains both understudied and poorly resolved.

Unlike pigments, which are selectively absorbent, structural colours result from the

60 selective reflectance of light by nano-structured tissues [10,11]. Accumulating evidence also

61 suggests that the development of these structures is driven by self-assembly — such as the phase

62 separation of keratin and cytoplasm in nascent feather barbs [12-14] - rather than the active

63 (and 'expensive') cellular processes that underlie some pigmentary colour production [8]. Three

64 general arguments have been articulated around their potential for honesty among structural 
65 colouration in sexual signalling. One is that if sufficient material is required to produce nano-

66 architectures then it will establish a trade-off with other physiological needs that may be

67 differentially met among individuals of varying 'quality', as consistent with a handicap

68 explanation [4,6]. A non-exclusive alternative builds on the observation that features of the

69 macro-scale expression of signals relies on the precision with which the underlying structures are

70 organised $[15,16]$. If individuals heritably vary in their capacity to achieve such organisation as a

71 result of, for example, physiological constraints on signal production, or the behavioural

72 acquisition of stable developmental environments, then signals may serve as an index of

73 underlying genetic quality [5]. Finally, the lack of obvious ecologically relevant material to

74 trade-off against during signal construction, together with the self-assembly inherent in structural

75 colours noted above, has motivated arguments against any general expectations for condition

76 dependence sensu lato [12]. Though experimental work is able to partition these hypotheses in

77 some contexts [17], most empirical studies to date have focused on the overarching question of

78 honesty by examining the predicted covariance between fitness-related traits and signal

79 expression. This has provided valuable insight into the central question, but diversity in signal

80 designs, measures of 'quality', and taxonomy have presented a challenge for qualitative

81 synthesis. Modern quantitative methods, however, provide robust tools for controlling for and

82 capitalising on such variation (e.g via mixed-effects models and meta-regression), and so can

83 offer substantive answers to longstanding questions [18].

84 Here I used phylogenetically controlled meta-analysis and meta-regression to examine

85 whether structural colour signals encode salient information on individual quality. Specifically, I

86 synthesised estimates of correlations between measures of individual quality and signal 
87 expression to test the prediction of condition dependence, before examining methodological and

88 theoretically derived mediators of effect-size variation among studies.

\section{Methods}

Literature search and study selection

I conducted a systematic literature search using Web of Knowledge and Scopus databases

92 for publications up to September 2019, using the query ((colour OR color OR pigment) AND

93 signal AND (quality OR condition OR condition dependent OR condition dependence OR

94 ornament) OR honest*), as well as searching the references of included texts. This produced

953482 unique studies, from which 41 were ultimately suitable for quantitative synthesis following

96 the screening of titles and abstracts (where $n=3430$ were excluded for clear irrelevance), and

97 full texts (see Fig. S1 for PRISMA statement). I used the R package 'revtools' v0.4.1 for title and

98 abstract screening [19]. I included all experimental and observational studies that quantified the

99 relationship between intersexual structural colour signal expression (via the measurement of hue,

100 saturation, or brightness, or a composite thereof) and any one of age, body condition (size, size-

101 corrected mass, or growth rate), immune function (oxidative damage, PHA response, circulating

102 CORT or testosterone) or parasite resistance as a measure of individual quality. I excluded

103 studies that conflated the structural and pigmentary contributions to signal expression during

104 measurement or manipulation, only studied sexually immature juveniles, focused exclusively on

105 intrasexual signalling, used human-subjective assessments of colouration (such as colour

106 swatches or viewer rankings), or which did not provide adequate data in the form of raw effect

107 sizes, or summary statistics or figures from which effect sizes might be estimated. 
I used the correlation coefficient, Pearson's r, transformed to Fisher's z (given its

110 preferable normalizing and variance-stabilizing qualities) as the effect size describing the

111 relationship between colouration and individual quality for meta-analysis. These effects were

112 extracted directly from text or figures, using the R package 'metadigitise' v1.0 [20], where

113 possible $(\mathrm{n}=102)$, or was otherwise converted from available test statistics or summary data $(\mathrm{n}=$

114 84).

\section{Meta-analyses}

116 I ran both phylogenetic multi-level meta-analytic (intercept-only, MLM) and multi-level

117 meta-regression (MLMR) models, using the package 'metafor' v2.1-0 [21] in R v3.5.2 [22].

118 Almost all studies reported multiple effects through the estimation of several colour metrics or

119 multiple measures of individual quality, so I included both a study- and observation-level

120 random effect in all models. From my MLM model I estimated a meta-analytic mean (i.e.,

121 intercept) effect size, which describes the overall support for the honesty of structural colour

122 signals. I accounted for phylogenetic non-independence between effect sizes in all models by

123 estimating relationships among species using the Open Tree of Life database [23], accessed via

124 the R package 'rotl' v3.0.10 [24]. Given the resulting tree topology, I estimated a correlation

125 matrix from branch lengths derived using Grafen's method [25] assuming node heights raised to

126 the power of 0.5 . Though this does not account for evolutionary divergence, it grants an

127 approximate estimate of relatedness by accounting for phylogenetic topology (Fig. S2).

128 I then used separate MLMR models to examine the effects of moderators, both theoretical

129 and methodological, which may be expected to alter the strength of the signal/quality 
130 relationship. These included the measure of individual quality used-body condition, age,

131 immune function, or parasite resistance (as defined above) — since 'quality' is multivariate

132 (discussed below). There is a suite of metrics available for measuring colour, though they

133 typically center on quantifying the perceptually relevant features of hue (the unique colour),

134 saturation (spectral purity), and brightness, or a composite thereof [26]. I therefore classified

135 every measure as such in order to test which, if any, signal features contain salient information

136 on mate quality. In broad terms, the greater nano-structural organisation and/or material required

137 to generate more saturated and (to a lesser extent) brighter signals predicts a positive correlation

138 between these features and individual quality. Signal hue, by contrast, is a directionless measure

139 in the sense that there is no clear biophysical reason for predicting consistent among-individual

140 shifts toward longer or shorter wavelengths as a function of individual quality across taxa, and so

141 I ignored the sign of correlations for estimates of hue alone. I also tested the effect of signal

142 iridescence (i.e. the presence/absence of iridescent colouration), which I coded according to

143 information presented in-text or via secondary sources (including personal observation). The

144 rationale was twofold. For one, all iridescence arises from coherent light-scattering [27]. All

145 things being equal, coherent light-scatterers demand a level of architectural organisation beyond

146 that of incoherent scatterers (i.e. white colours) and possibly non-iridescent colours too, and so

147 offers an indirect test of the hypothesised link between the demands of nano-scale organisation

148 and signal honesty $[14,16]$. Second, iridescence is an inherently temporal feature of visual

149 communication which may provide an additional or alternate conduit of information to potential

150 mates, above and beyond that which is possible using non-iridescent signals $(17,28,29$; though

151 this possibility remains unexplored directly). In both cases the prediction is a stronger correlation

152 between colouration and quality among iridescent, as opposed to non-iridescent, ornaments. 
153 Finally, and following the above, I secondarily examined the effects of both quality measures

154 and colour metrics within each of the four taxonomic classes represented across the literature. I

155 focused on these two moderators alone because potential taxonomic variation in the mechanistic

156 links between colouration and individual quality are most likely to manifest via these

157 moderators, and because the limited available data precludes the testing of all moderators on a

158 per-class basis (note that even within these moderators, estimates were not possible across all

159 taxonomic groups).

160 With respect to methodology I considered study type, given my inclusion of both

161 experimental and observational studies, as well as the sex of focal animals. I also coded whether

162 studies included measurements of non-sexual traits as controls in tests of heightened condition-

163 dependence (see discussion). The prediction being that that studies including non-sexual controls

164 may report larger effects than those without, given that many traits will scale with condition to

165 some extent [30]. Note that both signal iridescence and the presence of controls were coded as

166 binary $(0 / 1)$ for simplicity in testing their respective predictions.

\section{Publication bias}

168 I explored evidence for publication bias by visually inspecting funnel plots of effect sizes

169 versus standard errors (Fig. S3) and using an Egger's test on an intercept-only MLMA that 170 included the random effects described above [31].

\section{Data availability}

172 All data and code are available via GitHub (https://github.com/EaSElab-18/ms_metacol)

173 and are persistently archived through Zenodo (https://dx.doi.org/10.5281/zenodo.3718617). 


\section{$174 \quad$ Results}

The final dataset comprised 186 effect sizes, across 28 species, from 41 studies $[6,17$,

176 32-71]. Of those 186 effects, 117 were drawn from birds, 22 from insects, 28 from reptiles, and

17711 from arachnids (Table S1; Fig. S2). As predicted, I found a positive overall correlation (i.e.

178 meta-analytic mean effect) between individual quality and structural colour signal expression $(Z$

$179=0.1573,95 \% \mathrm{CI}=0.084$ to 0.231 ; Fig. 1 ; Table 1 ). The heterogeneity of effect sizes - that is,

180 the variation in effect size estimates after accounting for sampling error — was high $\left(\mathrm{I}^{2}=\right.$

$18180.42 \%, 95 \% \mathrm{CI}=77.26$ to 83.01$)$, as is typical of meta-analytic data in ecology and

182 evolutionary biology [72]. A small amount of heterogeneity was explained by among-study

183 effects $\left(I^{2}=14.21 \%, 95 \% \mathrm{CI}=8.97\right.$ to 20.20$)$, and only a very weak phylogenetic signal was

184 evident $\left(\mathrm{I}^{2}=2.17 \%, 95 \% \mathrm{CI}=1.18\right.$ to 3.47$)$.

185 Of the measures of quality considered, body condition and immune function were

186 reliably positively correlated with structural colour expression, while age and parasite resistance

187 were not (see Table 1 for all corresponding numerical results henceforth). This varied slightly

188 across taxa, however, with a robust effect of condition on colouration apparent across all groups,

189 while effects of age and parasite resistance we apparent among insects and bird, respectively

190 (table S2; though these estimates are based on limited within- and between-taxa samples). Both

191 the hue and brightness of signals were similarly informative channels on-whole, while

192 chromaticity was not consistently associated with individual quality across taxa (though this

193 varied by taxa; table S2), nor was any correlation apparent when composite measures of

194 colouration were used. Iridescent signals were subject to slightly stronger positive correlations

195 than non-iridescent signals across all measures of condition. Signal honesty was apparent among

196 males only though the weak, borderline effect and much smaller sample among females $(\mathrm{n}=$ 
$19729 / 186$ versus 146/186 for males) suggests a male bias in the literature similar to that in related

198 fields [73], which may have partly driven this outcome. Experimental studies tended to report

199 marginally stronger correlations than observational assays, which most likely reflects slightly

200 exaggerated experimental manipulations of condition relative to natural variation [30]. Finally,

201 the majority of studies $(n=36)$ did not include measurements of non-sexual control traits in tests

202 of heightened condition dependence, though I found no clear difference in effect-size estimates

203 between those that did and did not.

204 Publication bias

205 Visual inspection of the funnel plot showed little asymmetry (Fig. S3), as supported by 206 non-significant Egger's tests $\left(\mathrm{t}_{184}=-0.5535, \mathrm{p}=0.5806\right)$, which suggests a minimal influence of 207 missing data on effect size estimates.

\section{Discussion}

Ornamental colouration may be a reliable conduits of information on mate quality,

210 though evidence for the predicted covariance between signal expression and mate quality among

211 structural, as opposed to pigmentary, signals is equivocal. Here I found meta-analytic support for

212 this link in the form of a positive correlation between structural colour expression and individual

213 quality (Fig. 1), consistent with honesty-based models of sexual signal evolution [4,5]. The

214 strength of the overall correlation, though moderate [74], was commensurate with meta-analytic

215 estimates from pigment-based sexual signals $[8,9,75]$, and suggests that structural colouration

216 may similarly serve a reliable indicator of individual quality. 
Quality is a multivariate feature of individuals, and this is reflected in the effect-size

218 variation between measures. Both condition (as narrowly defined above), and proxy measures of

219 immune system integrity were on-average positively correlated with signal expression across all

220 taxa in which those relationships have been examined. This is consistent with experimental work

221 showing that body mass and immune function are responsive to ecologically salient stressors,

222 with consequences for colour production. Among birds, for example, disease and dietary stress

223 produce abnormalities in the keratin barbules that contribute to colouration [16,76,77], while in

224 butterflies the organisation of wing-scale architectures is disrupted by nutritional and

225 environmental stress during pupal (hence, wing-structure) development [36,78]. In contrast,

226 neither age nor parasite resistance were consistently informative of mate quality, though this

227 varied slightly across taxa. These latter measures are often predicated on, or susceptible to, the

228 mechanical degradation of structures post-development. Thus, the inherently heightened

229 variability of sexual signals combined with parasite-induced damage (ectoparasite, in particular)

230 and/or accumulated wear with age, combined with varied mechanisms of colour production of

231 across animal classes, may compound to render the signals less accurate predictors on balance

$232[59,79,80]$. Curiously, the near inverse relationship was recently identified in a meta-analysis of

233 carotenoid-based signalling. Weaver et al. [8] examined correlations across similar categories of

234 quality as those used here but found no consistent relationship between signals and either of

235 body condition or immune function. Given the fundamental optical and developmental

236 differences between structural and pigmentary colour production (described above) the potential

237 exists for each to signal unique aspects of individual mate quality, as is suggested by the totality

238 of this work. This has also been directly supported by limited empirical work [65] and may hold 
239 more broadly as an explanation for the often-integrated use of structural and pigmentary

240 mechanisms in sexual colouration.

241 Colour is often assumed to be the central conduit of information exchange given its

242 relative stability under variable natural illumination [81,82], though my results suggest both the

243 colour and brightness of signals are similarly informative, considering the evidence to date (Fig.

244 1; Table S2). Furthermore, I identified slightly stronger condition dependence among iridescent,

245 as opposed to non-iridescent, patches. While the underlying architecture varies across taxa, all

246 iridescent colouration arises from coherent light interference and so may demand a level of

247 architectural organisation beyond that of incoherent scattering [11,27], as well as non-iridescent

248 coherent scattering (though evidence for the latter possibility is limited; [14]). Iridescence also

249 introduces temporal structure to signals since the colour appearance depends on the precise

250 arrangement of signals, viewers, and light sources. These combined features may render

251 iridescent colouration particularly suitable as bearers of information [29] and so contribute to the

252 ubiquity of the phenomenon [83,84]. Though only indirectly considered here, as few studies

253 quantify between-individual variation in iridescence itself, this idea has found more immediate

254 support via condition-dependent variation in signal angularity [17], and a predictive relationship

255 between iridescence and mating success [85]. Empirically unravelling the function and

256 perceptual significance of iridescence in the context of sexual signalling-where the effect is

257 seen at its most extreme-remains an active challenge [28]. More generally, these results affirm

258 the view that the extended spectral and temporal repertoire available to structural colours may

259 facilitate the exploration of distinct 'signalling niches', with tangible evolutionary consequences

$260[1,54]$. 
By integrating the development of signal structure and fitness-related traits, structural

262 colours may serve as informative signals during mate choice. A holistic understanding, however,

263 awaits progress on several fronts. Most significant is the inclusion of appropriate non-sexual

264 controls. Given that many traits will scale with overall condition, the ultimate evidence for

265 handicap models lies in the demonstration of heightened condition-dependence among sexual

266 traits. Though I found no clear difference in effect size estimates between studies with and

267 without such controls the small sample size was limiting, and moreover represents a conceptual

268 limitation that remains pervasive [30]. Partitioning indicator and handicap models of signal

269 evolution and understanding the nature of direct and/or indirect benefits being signalled, are key

270 challenges which requires both experimental and quantitative-genetic study [17]. The

271 development of structural colours during ontogeny is also a central front for progress, and studies

272 among invertebrates (which offer benefits in terms of tractability) would be invaluable in

273 complementing the excellent work accumulating on birds [12-14]. Finally, signalling ecology

274 should remain front-of-mind as accumulating evidence, consistent with that presented here,

275 continues to highlight the inherent spatio-temporal complexity of signals and visual systems [86-

276 88]. This offers exciting opportunities for integrative studies of signal development, production,

277 and perception, which will fuel a richer view of this pervasive adornment of the natural world.

\section{Acknowledgments}

I'm grateful to Daniel Noble and Alistair Senior for advice on meta-analysis, and

280 Elizabeth Mulvenna and Cormac White for their endless support. I appreciate the efforts of three

281 anonymous reviewers whose thoughtful suggestions considerably improved this study. 
bioRxiv preprint doi: https://doi.org/10.1101/2020.01.01.892547; this version posted March 19, 2020. The copyright holder for this preprint (which was not certified by peer review) is the author/funder. All rights reserved. No reuse allowed without permission.

\section{$282 \quad$ Funding}

283 None to report.

284

285

286

287

288

289

290

291

292

293

294

295

296 


\section{References}

298 1. Maia R, Rubenstein DR, Shawkey MD. 2013 Key ornamental innovations facilitate 299 diversification in an avian radiation. Proceedings of the National Academy of Sciences 110, $300 \quad 10687-10692$.

301 2. Dalrymple RL, Flores-Moreno H, Kemp DJ, White TE, Laffan SW, Hemmings FA, Hitchcock 302 TD, Moles AT. 2018 Abiotic and biotic predictors of macroecological patterns in bird and 303 butterfly coloration. Ecological Monographs 88, 204-224.

304 3. Andersson MB. 1994 Sexual selection. Princeton, NJ: Princeton University Press.

305 4. Zahavi A. 1975 Mate selection—a selection for a handicap. Journal of Theoretical Biology 53, $306205-214$.

307 5. Maynard Smith J, Harper D. 2003 Animal signals. Oxford University Press.

308 6. Keyser AJ, Hill GE. 1999 Condition-dependent variation in the blue-ultraviolet coloration of 309 a structurally based plumage ornament. Proceedings of the Royal Society of London. Series B: 310 Biological Sciences 266, 771-777.

311 7. Kemp DJ. 2008 Resource-mediated condition dependance in sexually dichromatic butterfly 312 wing coloration. Evolution 62, 2346-2358.

313 8. Weaver RJ, Santos ES, Tucker AM, Wilson AE, Hill GE. 2018 Carotenoid metabolism 314 strengthens the link between feather coloration and individual quality. Nature communications 9 , 31573.

316 9. Simons MJ, Cohen AA, Verhulst S. 2012 What does carotenoid-dependent coloration tell? 317 Plasma carotenoid level signals immunocompetence and oxidative stress state in birds-a meta318 analysis. PLoS One 7, e43088.

319 10. Vukusic P, Sambles J. 2003 Photonic structures in biology. Nature 424, 852-5.

320 11. Johnsen S. 2012 The optics of life: A biologist's guide to light in nature. Princeton University 321 Press. 
322 12. Prum RO, Dufresne ER, Quinn T, Waters K. 2009 Development of colour-producing $\beta$ 323 keratin nanostructures in avian feather barbs. Journal of the Royal Society Interface 6, S253324 S265.

325 13. Dufresne ER, Noh H, Saranathan V, Mochrie SG, Cao H, Prum RO. 2009 Self-assembly of 326 amorphous biophotonic nanostructures by phase separation. Soft Matter 5, 1792-1795.

327 14. Maia R, Macedo RHF, Shawkey MD. 2011 Nanostructural self-assembly of iridescent 328 feather barbules through depletion attraction of melanosomes during keratinization. Journal of the Royal Society Interface (doi:10.1098/rsif.2011.0456)

330 15. Ghiradella HT, Butler MW. 2009 Many variations on a few themes: A broader look at 331 development of iridescent scales (and feathers). Journal of the Royal Society Interface, rsif3322008.

333 16. Shawkey MD, Estes AM, Siefferman LM, Hill GE. 2003 Nanostructure predicts intraspecific 334 variation in ultraviolet-blue plumage colour. Proc $R$ Soc $B$ 270, 1455-1460. 335 (doi:10.1098/rspb.2003.2390)

336 17. Kemp DJ, Rutowski RL. 2007 Condition dependence, quantitative genetics, and the potential 337 signal content of iridescent ultraviolet butterfly coloration. Evolution 61, 168-183.

338 18. Koricheva J, Gurevitch J, Mengersen K. 2013 Handbook of meta-analysis in ecology and 339 evolution. Princeton University Press.

340 19. Westgate MJ. 2019 Revtools: An r package to support article screening for evidence 341 synthesis. Research synthesis methods

342 20. Pick JL, Nakagawa S, Noble DW. 2019 Reproducible, flexible and high-throughput data 343 extraction from primary literature: The metaDigitise $\mathrm{r}$ package. Methods in Ecology and 344 Evolution 10, 426-431.

345 21. Viechtbauer W. 2010 Conducting meta-analyses in r with the metafor package. Journal of 346 Statistical Software 36, 1-48. 
347 22. R Core Team. 2018 R: A language and environment for statistical computing. Vienna, 348 Austria: R Foundation for Statistical Computing. See https://www.R-project.org/.

349 23. Hinchliff CE et al. 2015 Synthesis of phylogeny and taxonomy into a comprehensive tree of 350 life. Proceedings of the National Academy of Sciences 112, 12764-12769.

351 24. Michonneau F, Brown JW, Winter DJ. 2016 Rotl: An r package to interact with the open tree 352 of life data. Methods in Ecology and Evolution 7, 1476-1481.

353 25. Grafen A. 1989 The phylogenetic regression. Philosophical Transactions of the Royal 354 Society of London. B, Biological Sciences 326, 119-157.

355 26. Maia R, White TE. 2018 Comparing colors using visual models. Behavioral Ecology 29, 356 649-659.

357 27. Prum RO. 2006 Anatomy, physics, and evolution of structural colors. Bird coloration 1, 295358353.

359 28. White TE. 2018 Illuminating the evolution of iridescence. Trends in Ecology \& Evolution 33, $360 \quad 374-375$.

361 29. Rutowski RL, Merry JW, Morehouse NI, Yturralde K, Taylor-Taft L, Gaalema D, Kemp DJ, 362 Papke RS. 2007 Iridescent ultraviolet signal in the orange sulphur butterfly (colias eurytheme): 363 Spatial, temporal and spectral properties. Biological Journal of the Linnean Society 90, 349-364.

364 30. Cotton S, Fowler K, Pomiankowski A. 2004 Do sexual ornaments demonstrate heightened 365 condition-dependent expression as predicted by the handicap hypothesis? Proceedings of the 366 Royal Society of London. Series B: Biological Sciences 271, 771-783.

367 31. Egger M, Smith GD, Schneider M, Minder C. 1997 Bias in meta-analysis detected by a 368 simple, graphical test. BMJ 315, 629-634.

369 32. D'Alba L, Van Hemert C, Handel CM, Shawkey MD. 2011 A natural experiment on the 370 condition-dependence of achromatic plumage reflectance in black-capped chickadees. PLoS One 3716 . 
372 33. Taylor LA, Clark DL, McGraw KJ. 2011 Condition dependence of male display coloration in 373 a jumping spider (habronattus pyrrithrix). Behavioral Ecology and Sociobiology 65, 1133-1146.

374 34. Barry KL, White TE, Rathnayake DN, Fabricant SA, Herberstein ME. 2015 Sexual signals 375 for the colour-blind: Cryptic female mantids signal quality through brightness. Functional 376 Ecology 29, 531-539.

377 35. Peters A, Kurvers R, Roberts ML, Delhey K. 2011 No evidence for general condition378 dependence of structural plumage colour in blue tits: An experiment. Journal of evolutionary 379 biology 24, 976-987.

380 36. Kemp DJ. 2008 Resource-mediated condition dependence in sexually dichromatic butterfly 381 wing coloration. Evolution: international journal of organic evolution 62, 2346-2358.

382 37. Megía-Palma R, Martínez J, Merino S. 2016 A structural colour ornament correlates 383 positively with parasite load and body condition in an insular lizard species. The Science of $384 \quad$ Nature 103, 52.

385 38. Siefferman L, Hill GE, Dobson FS. 2005 Ornamental plumage coloration and condition are 386 dependent on age in eastern bluebirds sialia sialis. Journal of Avian Biology 36, 428-435.

39. Perrier C, Lope F de, Møller AP, Ninni P. 2002 Structural coloration and sexual selection in the barn swallow hirundo rustica. Behavioral Ecology 13, 728-736.

389 40. Doucet SM. 2002 Structural plumage coloration, male body size, and condition in the blue390 black grassquit. The Condor 104, 30-38.

391 41. Smiseth PT, Örnborg J, Andersson S, Amundsen T. 2001 Is male plumage reflectance 392 correlated with paternal care in bluethroats? Behavioral Ecology 12, 164-170.

393 42. Keyser AJ, Hill GE. 2000 Structurally based plumage coloration is an honest signal of 394 quality in male blue grosbeaks. Behavioral Ecology 11, 202-209.

395 43. Schull Q, Dobson FS, Stier A, Robin J-P, Bize P, Viblanc VA. 2016 Beak color dynamically 396 signals changes in fasting status and parasite loads in king penguins. Behavioral Ecology, 397 arw091. 
44. Henderson LJ, Heidinger BJ, Evans NP, Arnold KE. 2013 Ultraviolet crown coloration in female blue tits predicts reproductive success and baseline corticosterone. Behavioral Ecology 24, 1299-1305.

401 45. Zirpoli JA, Black J, Gabriel P. 2013 Parasites and plumage in steller's jays: An experimental 402 field test of the parasite-mediated handicap hypothesis. Ethology Ecology \& Evolution 25, 103403116.

404 46. Freeman-Gallant CR, Taff CC, Morin DF, Dunn PO, Whittingham LA, Tsang SM. 2010 405 Sexual selection, multiple male ornaments, and age-and condition-dependent signaling in the 406 common yellowthroat. Evolution: International Journal of Organic Evolution 64, 1007-1017.

407 47. Nicolaus M, Le Bohec C, Nolan PM, Gauthier-Clerc M, Le Maho Y, Komdeur J, Jouventin 408 P. 2007 Ornamental colors reveal age in the king penguin. Polar Biology 31, 53-61.

409 48. Quinard A, Cézilly F, Motreuil S, Rossi J-M, Biard C. 2017 Reduced sexual dichromatism, 410 mutual ornamentation, and individual quality in the monogamous zenaida dove zenaida aurita. 411 Journal of Avian Biology 48, 489-501.

412 49. Molnár O, Bajer K, Mészáros B, Török J, Herczeg G. 2013 Negative correlation between 413 nuptial throat colour and blood parasite load in male european green lizards supports the 414 hamilton-zuk hypothesis. Naturwissenschaften 100, 551-558.

415 50. Grindstaff JL, Lovern MB, Burtka JL, Hallmark-Sharber A. 2012 Structural coloration 416 signals condition, parental investment, and circulating hormone levels in eastern bluebirds (sialia 417 sialis). Journal of Comparative Physiology A 198, 625-637.

418 51. Bajer K, Molnar O, Török J, Herczeg G. 2012 Temperature, but not available energy, affects 419 the expression of a sexually selected ultraviolet (uv) colour trait in male european green lizards. $420 \quad$ PLoS One 7, e34359.

421 52. Roberts ML, Ras E, Peters A. 2009 Testosterone increases uv reflectance of sexually selected 422 crown plumage in male blue tits. Behavioral Ecology 20, 535-541. 
423 53. Silva N, Avilés JM, Danchin E, Parejo D. 2008 Informative content of multiple plumage-

424 coloured traits in female and male european rollers. Behavioral Ecology and Sociobiology 62, 4251969.

426 54. Bitton P-P, Dawson RD. 2008 Age-related differences in plumage characteristics of male tree 427 swallows tachycineta bicolor: Hue and brightness signal different aspects of individual quality. 428 Journal of Avian Biology 39, 446-452.

429 55. Balenger SL, Scott Johnson L, Brubaker JL, Ostlind E. 2007 Parental effort in relation to 430 structural plumage coloration in the mountain bluebird (sialia currucoides). Ethology 113, 838431846.

432 56. Siitari H, Alatalo RV, Halme P, Buchanan KL, Kilpimaa J. 2007 Color signals in the black 433 grouse (tetrao tetrix): Signal properties and their condition dependency. The American Naturalist 434 169, S81-S92.

435 57. Mougeot F, Arroyo BE. 2006 Ultraviolet reflectance by the cere of raptors. Biology Letters 2 , $436 \quad 173-176$.

437 58. Kemp DJ, Vukusic P, Rutowski R. 2006 Stress-mediated covariance between nano-structural 438 architecture and ultraviolet butterfly coloration. Functional Ecology 20, 282-289.

439 59. Kemp DJ. 2006 Heightened phenotypic variation and age-based fading of ultraviolet 440 butterfly wing coloration. Evolutionary Ecology Research 8, 515-527.

441 60. Peters A, Delhey K, Goymann W, Kempenaers B. 2006 Age-dependent association between 442 testosterone and crown uv coloration in male blue tits (parus caeruleus). Behavioral Ecology and 443 Sociobiology 59, 666-673.

444 61. Mougeot F, Redpath SM, Leckie F. 2005 Ultra-violet reflectance of male and female red 445 grouse, lagopus lagopus scoticus, sexual ornaments reflect nematode parasite intensity. Journal 446 of Avian Biology 36, 203-209.

447 62. Hill GE, Doucet SM, Buchholz R. 2005 The effect of coccidial infection on iridescent 448 plumage coloration in wild turkeys. Animal Behaviour 69, 387-394. 
63. Doucet SM, Montgomerie R. 2003 Multiple sexual ornaments in satin bowerbirds:

450 Ultraviolet plumage and bowers signal different aspects of male quality. Behavioral Ecology 14,

$451503-509$.

452 64. Hahn S, Peter H-U. 2003 Sex and age dependency of wing patch size in brown skuas. Emu $453103,37-41$.

454 65. McGraw KJ, Mackillop EA, Dale J, Hauber ME. 2002 Different colors reveal different 455 information: How nutritional stress affects the expression of melanin-and structurally based 456 ornamental plumage. Journal of Experimental Biology 205, 3747-3755.

457 66. Molnár O, Bajer K, Török J, Herczeg G. 2012 Individual quality and nuptial throat colour in 458 male e uropean green lizards. Journal of Zoology 287, 233-239.

459 67. Griggio M, Zanollo V, Hoi H. 2010 UV plumage color is an honest signal of quality in male 460 budgerigars. Ecological Research 25, 77-82.

461 68. Viblanc VA et al. 2016 Mutually honest? Physiological 'qualities' signalled by colour 462 ornaments in monomorphic king penguins. Biological Journal of the Linnean Society 118, 200463214.

464 69. Lim ML, Li D. 2006 Effects of age and feeding history on structure-based uv ornaments of a 465 jumping spider (araneae: Salticidae). Proceedings of the Royal Society B: Biological Sciences $466274,569-575$.

467 70. Bitton P-P, Dawson RD, Ochs CL. 2008 Plumage characteristics, reproductive investment 468 and assortative mating in tree swallows tachycineta bicolor. Behavioral Ecology and 469 Sociobiology 62, 1543-1550.

470 71. Beck ML, Hopkins WA, Hawley DM. 2015 Relationships among plumage coloration, blood 471 selenium concentrations and immune responses of adult and nestling tree swallows. Journal of 472 Experimental Biology 218, 3415-3424.

473 72. Senior AM, Grueber CE, Kamiya T, Lagisz M, O’dwyer K, Santos ES, Nakagawa S. 2016 474 Heterogeneity in ecological and evolutionary meta-analyses: Its magnitude and implications. 475 Ecology 97, 3293-3299. 
73. Ah-King M, Barron AB, Herberstein ME. 2014 Genital evolution: Why are females still 477 understudied? PLoS Biology 12, e1001851.

478 74. Cohen J. 1998 Statistical power analysis for the behavioral sciences. Routledge.

479 75. Griffith SC, Parker TH, Olson VA. 2006 Melanin- versus carotenoid-based sexual signals: Is 480 the difference really so black and red? Animal Behaviour 71, 749-763. 481 (doi:10.1016/j.anbehav.2005.07.016)

482 76. Murphy ME, King JR, Lu J. 1988 Malnutrition during the postnuptial molt of white-crowned 483 sparrows: Feather growth and quality. Canadian Journal of Zoology 66, 1403-1413.

484 77. Negro Juan Jose, Bildstein KL, Bird DM. 1994 Effects of food deprivation and handling 485 stress on fault-bar formation in nestling american kestrels (falco sparverius). ARDEA 82, 263486267.

487 78. Kemp DJ, Vukusic P, Rutowski RL. 2006 Stress-mediated covariance between nano488 structural architecture and ultraviolet butterfly coloration. Functional Ecology 20, 282-289. 489 (doi:10.1111/j.1365-2435.01100.x)

490 79. Cotton S, Fowler K, Pomiankowski A. 2004 Condition dependence of sexual ornament size 491 and variation in the stalk-eyed fly cyrtodiopsis dalmanni (diptera: Diopsidae). Evolution 58, $492 \quad 1038-1046$.

493 80. Pomiankowski A, Møller AP. 1995 A resolution of the lek paradox. Proceedings of the Royal 494 Society of London. Series B: Biological Sciences 260, 21-29.

495 81. Gegenfurtner KR, Kiper DC. 2003 Color vision. Annual Review of Neuroscience 26.

496 82. Rubin JM, Richards W. 1982 Color vision and image intensities: When are changes material? 497 Biological Cybernetics 45, 215-226.

498 83. Seago AE, Brady P, Vigneron J-P, Schultz TD. 2009 Gold bugs and beyond: A review of 499 iridescence and structural colour mechanisms in beetles (coleoptera). Journal of the Royal 500 Society Interface 6, S165-S184. (doi:10.1098/rsif.2008.0354.focus) 
501 84. White TE, Macedonia J, Birch D, Dawes J, Kemp DJ. 2012. The nanoanatomical basis of

502 sexual dimorphism in iridescent butterfly colouration. Australian Journal of Zoology, 60(2), 101503107.

504 85. Loyau A, Gomez D, Moureau BT, Thery M, Hart NS, Saint Jalme M, Bennett ATD, Sorci G. 5052007 Iridescent structurally based coloration of eyespots correlates with mating success in the 506 peacock. Behavioral Ecology 18, 1123-1131.

507 86. Hogan BG, Stoddard MC. 2018 Synchronization of speed, sound and iridescent color in a 508 hummingbird aerial courtship dive. Nature Communications 9.

509 87. White TE, Zeil J, Kemp DJ. 2015 Signal design and courtship presentation coincide for 510 highly biased delivery of an iridescent butterfly mating signal. Evolution 69, 14-25.

511 88. Foster DH, Amano K, Nascimento SM. 2001 How temporal cues can aid colour constancy.

512 Color Research \& Application 26, S180-S185.

513

514

515

516 
524 Table 1: Full parameter estimates from MLM and MLMR models of the mediators of the 525 correlation between structural colour signal expression and individual quality. Shown are 526 sample sizes, mean Fisher's $\mathrm{z}$ values and lower and upper 95\% confidence intervals, and 527 heterogeneity. Estimates whose 95\% confidence intervals do not overlap zero are indicated in 528 bold. Note that iridescence and the inclusion of controls are coded as binary (0/1), and so 529 represent a test of difference in effect-sizes between their counterpart categories (see main text).

\begin{tabular}{lccccc}
\hline Model & $\mathbf{n}$ & Mean (Zr) & Lower CI & Upper CI & $\mathbf{I}^{2}$ (\%) \\
\hline Overall (intercept-only) & 186 & $\mathbf{0 . 1 5 7}$ & $\mathbf{0 . 0 8 4}$ & $\mathbf{0 . 2 3 1}$ & 80.42 \\
Quality measure & & & & & 79.96 \\
$\quad 37$ & 0.015 & -0.119 & 0.148 & \\
$\quad$ age & 102 & $\mathbf{0 . 1 9 0}$ & $\mathbf{0 . 0 9 9}$ & $\mathbf{0 . 2 8 2}$ & \\
$\quad$ body condition & 11 & $\mathbf{0 . 3 5 3}$ & $\mathbf{0 . 1 2 6}$ & $\mathbf{0 . 5 8 0}$ & \\
$\quad$ immune function & 36 & 0.114 & -0.023 & 0.252 & \\
$\quad$ parasite resistance & & & & & 80.32 \\
Component & 50 & $\mathbf{0 . 2 2 4}$ & $\mathbf{0 . 1 2 3}$ & $\mathbf{0 . 3 4 5}$ & \\
$\quad$ hue & 57 & 0.076 & -0.029 & 0.181 & \\
$\quad$ saturation & 60 & $\mathbf{0 . 1 7 1}$ & $\mathbf{0 . 0 7 9}$ & $\mathbf{0 . 2 6 4}$ & \\
$\quad$ brightness & 19 & 0.120 & -0.056 & 0.296 & \\
$\quad$ composite & & & & & \\
Sex & 29 & 0.131 & -0.004 & 0.267 & \\
$\quad$ female & 146 & $\mathbf{0 . 1 6 1}$ & $\mathbf{0 . 0 8 0}$ & $\mathbf{0 . 2 4 1}$ & \\
$\quad$ male & 11 & 0.183 & -0.046 & 0.413 & \\
$\quad$ not distinguished & & & & & \\
Study type & 52 & $\mathbf{0 . 2 1 6}$ & $\mathbf{0 . 1 0 4}$ & $\mathbf{0 . 3 2 9}$ & \\
$\quad \begin{array}{l}\text { experimental } \\
\text { observational }\end{array}$ & 134 & $\mathbf{0 . 1 2 8}$ & $\mathbf{0 . 0 5 8}$ & $\mathbf{0 . 1 9 9}$ & \\
Optics & & & & & \\
$\quad$ iridescent (vs not) & 67 & $\mathbf{0 . 1 5 0}$ & $\mathbf{0 . 0 0 9}$ & $\mathbf{0 . 2 9 1}$ & \\
Control & & & & & \\
$\quad$ included (vs not) & 28 & 0.071 & -0.117 & 0.260 & \\
\hline
\end{tabular}



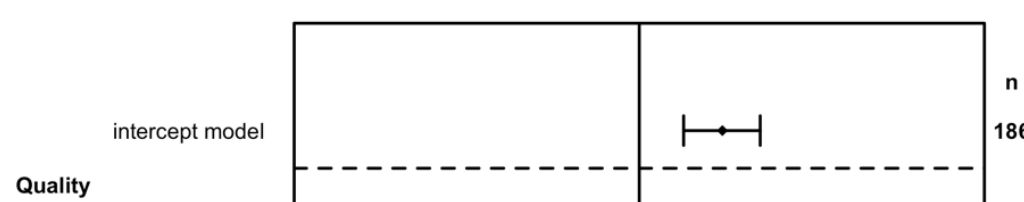

Quality
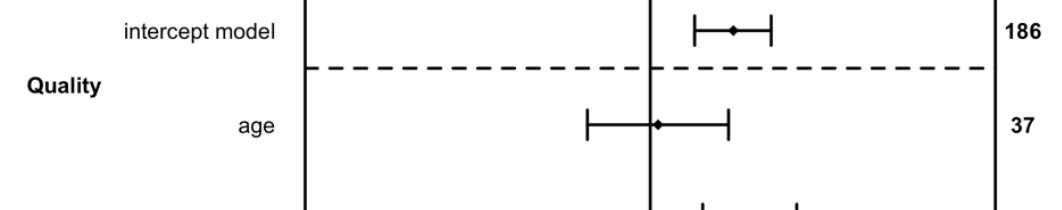

540

541

Component

542

543

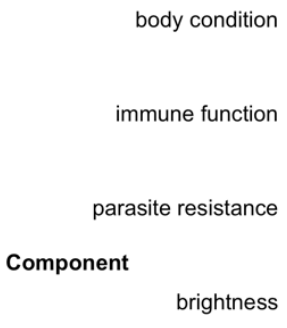

chroma

544

545

Sex

546

547

548

female

composite

male

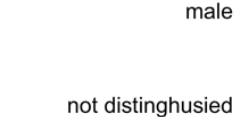

Study

not distinghusied

549

550

551

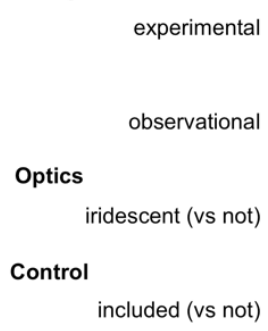

552

553

$$
\text { included (vs not) }
$$

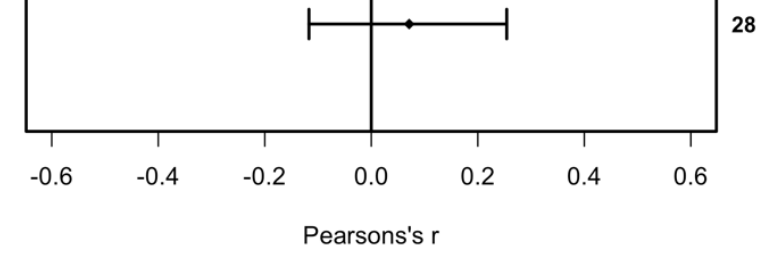

554 Figure 1: Forest plot of the mediators of the correlation between structural colour signal

555 expression and individual quality. Shown are Pearson's correlations back transformed from

556 Fisher's $\mathrm{z}$, with 95\% confidence intervals about the mean. Sample sizes are displayed on the

557 right. 'Composite' refers to measures that conflate hue, saturation, and brightness (such as

558 PCA), while 'not distinguished' refers to studies in which the sex of focal animals was either not

559 specified, or males and females were pooled. Note that iridescence and the inclusion of controls

560 are coded as binary $(0 / 1)$, and so represent a test of difference in effect-sizes between their

561 counterpart categories (see main text). 
bioRxiv preprint doi: https://doi.org/10.1101/2020.01.01.892547; this version posted March 19, 2020. The copyright holder for this preprint (which was not certified by peer review) is the author/funder. All rights reserved. No reuse allowed without permission.

562

563

564

565

566

567

568

569

570

571

572

573

574

575

576

577

578

579

580

581 